\title{
Comentários sobre a concepção objetiva do intelecto em Schopenhauer a partir da leitura dos Complementos ao Mundo como vontade e representação
}

\author{
Comments on the objective conception of the intellect in Schopenhauer \\ from the reading of the Complements to "The World as Will and \\ Representation"
}

\author{
André Luiz Simões Pedreira \\ Mestre em Filosofia da Educação pela Faculdade de Educação da Universidade \\ Federal da Bahia (UFBA/FACED). Professor Assistente de Epistemologia e Filosofia \\ da Universidade do Estado da Bahia (UNEB) \\ E-mail: andreluiz.pedreira@hotmail.com
}

\begin{abstract}
Resumo: Nosso artigo pretendeu comentar as teses da concepção de intelecto em Schopenhauer a partir da leitura dos Complementos a $O$ mundo como vontade e representação. Esta concepção, portanto, toma o intelecto como um elemento fenomênico e fisiológico, opondo-se, portanto, à concepção contida no primeiro livro de $O$ mundo como vontade e representação, que toma o intelecto como transcendental. Porém, não se constituiu como objetivo deste artigo analisar os aspectos peculiares desse duplo ponto de vista acerca do intelecto, que não são contraditórios, mas complementares, pois independentemente do ponto de vista que seja pensado, o intelecto não ultrapassa sua natureza física, isto é, fenomênica, estando, por conseguinte, submetido às condições temporais.
\end{abstract}

Palavras-chave: Intelecto; Fisiológico; Instrumental.

\begin{abstract}
Our article sought to review the theses of the vision of the intellect in Schopenhauer from reading supplements of the World as Will and Representation. This view, therefore, takes the intellect as an element phenomenal and physiological opposing therefore the vision contained in the first book of the World as Will and Representation, which takes the intellect as transcendental. However, it was not an aim of this article to analyze the peculiar aspects of this dual viewpoint on the intellect, which are not contradictory, but complementary, independent point of view it is thought, the intellect does not exceed its physical nature, ie, phenomenal and is therefore subject to temporal conditions.
\end{abstract}

Key-words: Intellect; Physiological; Instrumental. 


\title{
I - Introdução
}

\begin{abstract}
Todos os filósofos erraram ao terem posto o metafísico, o indestrutível, o eterno do homem no intelecto: ele está exclusivamente na Vontade, que é completamente diferente dele e é unicamente originária. $\mathrm{O}$ intelecto, como exposto a fundo no segundo livro, é um fenômeno secundário e condicionado pelo cérebro, por conseguinte começa e termina com ele .
\end{abstract}

Schopenhauer dedicou-se a uma produção exaustiva sobre o tema do intelecto, que se encontra disseminada em suas obras, mais especificamente naquelas que tratam da Teoria do Conhecimento ${ }^{2}$, a saber, em Sobre a quádrupla raiz do princípio de razão suficiente (1813), no primeiro livro de $O$ mundo como vontade e representação seguido do apêndice intitulado Crítica da filosofia kantiana (1818), em Da vontade na natureza (1836) e nos Complementos aos livros primeiro e segundo de $O$ mundo como vontade $e$ representação (1844). Tais obras encarregam-se de apresentar a visão objetiva e subjetiva do intelecto concebida pelo filósofo, por um lado como fenomênico e fisiológico e, por outro, como transcendental. Porém, não nos ocuparemos em analisar os aspectos peculiares desse duplo ponto de vista acerca do intelecto, que não são contraditórios, mas complementares. O intelecto, independente do ponto de vista que seja pensado, não ultrapassa sua natureza física, isto é, fenomênica, estando submetido às condições temporais.

Ao ter admitido o caráter secundário e instrumental do intelecto diante da Vontade irracional, seu conceito mor, Schopenhauer não se tornou um ferrenho opositor do intelecto, uma vez que em sua filosofia o mesmo torna-se um poderoso componente, dado à extensão do conhecimento que lhe é possível em vista da possibilidade da contemplação estética, da vida ética e da santidade naqueles indivíduos considerados como tipos superiores de homem, a saber, o gênio, o compassivo e o asceta. Estes, por uma graça da natureza, possuem um excesso de inteligência que os permite uma libertação dos grilhões da afirmação da vontade a partir da contemplação da ideia, no

\footnotetext{
${ }^{1}$ SCHOPENHAUER, A. O mundo como vontade e representação. Vol. II, p. 549.

${ }^{2}$ Todas as obras de Schopenhauer que tratam da Teoria do Conhecimento são tributárias de seus estudos de Medicina e Frenologia realizados em 1809, na Universidade de Göttingen, considerada entre as melhores da Europa. A frenologia era uma ciência da época que estudava os limites e possibilidades das ações humanas a partir da conformação craniana. Todas as características que ele atribuiu ao intelecto estão assentadas sob essa formação obtida. Durante esse período, alcançou uma ampla formação em ciências físicas e naturais. Cf. WEISSMANN, K. Vida de Schopenhauer, p. 53-54).
} 
caso do gênio, e do reconhecimento da vontade enquanto essência de todas as coisas, no caso do compassivo e do santo, com o que se daria a identidade do sujeito do querer com o sujeito do conhecer. Essa visão do intelecto como instrumental e pragmático, encontrada nos Complementos a $O$ mundo, que se propôs a mostrar o intelecto como algo objetivo e material, embora pareça contraditória à sua visão transcendental encontrada no primeiro livro do Mundo, não se constitui, segundo a nossa leitura, como uma posição que busca diminuir a visão filosófica das operações intelectuais, a exemplo da validade do princípio de razão suficiente, forma de conhecimento ligado ao serviço/afirmação da vontade.

A libertação da vontade alcançada pelos tipos superiores de homem encontrados nos livros III e IV de $O$ mundo dá-se por meio do conhecimento intuitivo, que se diferencia do conhecimento racional e abstrato. Isso aponta para a contradição estabelecida na ética schopenhaueriana, dado o deslocamento da liberdade, própria ao em si, para o fenômeno, já que uma das teses da psicologia de Schopenhauer afirma a primazia da vontade sobre o intelecto. Nos tipos superiores de homem, por sua vez, o intelecto perde o seu caráter permanente de instrumentalidade, como é perceptível no homem vulgar e nos animais, cuja vontade encontra-se voltada unicamente para querer "existência, bem-estar, vida e propagação da espécie"3.

Na filosofia de Schopenhauer, mais especificamente nos Complementos ao Mundo, o intelecto é considerado físico, isto é, fenomenal, enquanto a Vontade é metafísica. A Vontade objetiva-se no corpo, sendo o intelecto a parte do corpo representada pelo cérebro, que possibilita a relação intersubjetiva deste corpo individual com os outros corpos. Por ser físico, o intelecto como todo o mundo orgânico e inorgânico é objetidade/manifestação dessa Vontade, que se mostra em fenômenos, que variam em graus de visibilidade, mas que não se diferenciam em essência. O intelecto, por sua vez, encontra-se submetido à Vontade, porém, essa subordinação só é absoluta em termos metafísicos e nos baixos graus de objetivação da Vontade, a saber, nas forças inorgânicas, vegetais e animais não racionais. No plano físico, dado a identidade da vontade com o corpo humano, os tipos superiores de homem tornam-se capazes não de subordinar a vontade de modo peremptório, mas de se separarem/libertarem dela, uma vez que neles o intelecto consegue se desvencilhar das demandas que esta lhes impõe,

\footnotetext{
${ }^{3}$ SCHOPENHAUER, A. O mundo como vontade e representação. Vol. II, p. 242. 
exceto nos casos em que os movimentos do corpo acontecem sem qualquer indício de conhecimento, através de excitações, a saber, nos processos de digestão, circulação sanguínea, secreção e crescimento e, também, no tipo de homem chamado de vulgar por Schopenhauer, em que não há primazia do intelecto sobre a vontade. Homem este em que o intelecto permanece permanentemente em sua função instrumental e, por conseguinte, secundária em relação à vontade.

Como faculdade desenvolvida para servir a vontade, o intelecto é que torna possível o conhecimento e as representações. As representações, por conseguinte, possuem duas metades essenciais, a saber, o sujeito e o objeto. O objeto tem por formas o espaço e o tempo, enquanto o sujeito "não se encontra no espaço nem no tempo, pois está inteiro e indiviso em cada ser que representa"4. Segundo Schopenhauer, tratam-se de duas metades inseparáveis, sendo que "cada uma delas possui significação e existência apenas por e para a outra; cada uma existe com a outra e desaparece com ela. Elas se limitam imediatamente: onde começa o objeto, termina o sujeito"5. O que se conhece, por sua vez, através do intelecto em suas formas espaço, tempo e causalidade, também denominadas de princípio de razão, são apenas fenômenos, visto que o conhecimento da essência das coisas, ou seja, da Vontade, subtrai-se a uma dessas formas, a saber, o tempo, sendo este conhecimento reservado a experiência interna que cada indivíduo tem do seu próprio corpo, que se dá de modo intuitivo e imediato, onde os indivíduos se descobrem como sujeitos volitivos. Esse conhecimento obtido pela experiência interna ainda é representação, mas do ponto de vista da Vontade, que se constitui como o ponto de vista complementar ao ponto de vista da representação, é limitado pelo conhecimento de fenômeno ${ }^{6}$.

De tudo o que foi dito se segue que a Vontade como coisa-em-si encontra-se fora do domínio do princípio de razão e todas as suas figuras, e, por conseguinte, é absolutamente sem fundamento, embora cada um de seus fenômenos esteja por inteiro submetido ao princípio

\footnotetext{
${ }^{4}$ SCHOPENHAUER, A. O mundo como vontade e representação, p. 46.

${ }^{5}$ Idem, ibidem.

6 “A filosofia de Schopenhauer permite, pois, conceber como parte integrante do aparelho psíquico e da sua função de conhecer algo que está excluído do âmbito do conhecer. Reconhece ao que é semconsciência (bewustlos) ou, etimologicamente "não cognoscente" (nicht-wissend) um significado positivo, conferindo-lhe o estatuto de um objeto de saber. Não porém de um objeto de saber entre outros, mas de um objeto por excelência, na medida em que torna, ao mesmo tempo, possível a atividade do conhecer". Cf. CACCIOLA, M. L. M. O. Schopenhauer e o inconsciente. In: (Org.) KNOBLOCH, F. $O$ inconsciente: várias leituras, p. 25.
} 
Revista Voluntas: Estudos sobre Schopenhauer - Vol. 4, № 1 - 1º semestre de 2013 - ISSN: 2179-3786 - pp. 98-113.

de razão ${ }^{7}$

O intelecto no corpo humano é o próprio cérebro, que é objetidade da Vontade por ser parte do corpo. Porém, isso não implica em reducionismo do intelecto ao cérebro, embora, na visão do livro primeiro do Mundo como vontade e representação este é entendido como uma parte física de um complexo aparato psíquico, uma vez que sua descrição, nesta obra, faz parte de uma filosofia transcendental, ou seja, de um idealismo transcendental. Este órgão, o cérebro, é a própria faculdade do conhecimento, onde tudo o que é fenômeno só pode ser objeto de conhecimento mediante as formas do princípio de razão, que são a priori. Estas encontram-se no entendimento ou intelecto (Verstand), antes da experiência, sendo, pois, condições de sua possibilidade. Assim sendo, todo objeto exige necessariamente um sujeito que o capte nas formas do princípio de razão. Aqui, Schopenhauer mantém-se kantiano, ao dizer que:

Aprendemos do grande Kant que tempo, espaço e causalidade encontram-se em nossa consciência segundo sua completa legalidade e possibilidade de todas as suas formas, inteiramente independentes dos objetos que neles aparecem e que constituem o seu conteúdo, ou, noutros termos, eles podem ser encontrados quer se parta do sujeito, quer se parta do objeto; daí com igual direito poder-se denominá-los modos de intuição do sujeito ou qualidade do objeto ENQUANTO OBJETO (em Kant fenômeno), ou seja, REPRESENTAÇÃO ${ }^{8}$.

Os animais também possuem intelecto, embora sejam carentes da faculdade de razão, que é específica dos homens. Tanto nos animais quanto nos homens, a Vontade está em constante atividade, mas, diferente dos animais, nos quais essa atividade se realiza de maneira cega, acompanhada tão somente de conhecimento intuitivo, no homem o conhecimento abstrato ou racional chega a conduzir essa atividade, pois se torna capaz de transformar o conhecimento intuitivo em conhecimento abstrato, graças à razão, propondo motivos/representações para colocar a vontade em atividade. Por tornar a vontade e o intelecto comuns ao homem e aos animais, percebe-se que em Schopenhauer, "a diferença entre o homem e o animal não repousa na distinção entre vontade e intelecto, mas na separação entre intelecto e razão" ${ }^{\text {. }}$. O desenvolvimento da faculdade racional, nos indivíduos, desafixou-os da certeza da infalibilidade do instinto, perceptível claramente nos animais, deixando-lhes entregues ao erro e à hesitação.

\footnotetext{
${ }^{7}$ SCHOPENHAUER, A. O mundo como vontade e representação, p. 171-72.

${ }^{8}$ SCHOPENHAUER, A. O mundo como vontade e representação. p. 179.

${ }^{9}$ SANTANA, K. B. Sobre a IV motivação na psicologia de Schopenhauer, p. 184. 
Segundo a perspectiva dos Complementos, que se restringe a uma concepção fisiológica do intelecto, a faculdade de conhecimento tem, pois, o seu início com o aparecimento do cérebro e, por conseguinte, sua cessação com o seu desaparecimento. Isso acentua a temporalidade do intelecto, cuja "função principal é a autopreservação do indivíduo" ${ }^{10}$. Por sua condição física, o intelecto encontra-se fadado ao perecimento, isto é, ao enfraquecimento de suas forças, enquanto que a Vontade permanece imune aos efeitos do tempo, pois se encontra fora dele, uma vez que é identificada com a coisa-em-si. Contudo, o desaparecimento da atividade cerebral em um indivíduo, com a emergência da morte, não aniquila aquilo que é sua essência/Vontade, mas apenas o cérebro e suas formas a priori do espaço e do tempo, que perecem juntamente com o indivíduo. Na ausência de movimentos corporais, com o advento da morte, atuam as forças inorgânicas naquilo que foi orgânico, já que as Ideias ${ }^{11}$ vivem em permanente conflito pela posse da matéria.

O filósofo acentua a temporalidade e a finitude do intelecto em oposição à Vontade imutável e intemporal [...] Schopenhauer menciona com insistência a possibilidade da decrepitude, derradeiro grau de enfraquecimento do intelecto, a salvo da qual nenhum espírito pode se acreditar, se é verdade que ela atinge muitas vezes os melhores, ou aqueles que de alguma forma abusaram do intelecto ${ }^{12}$.

Schopenhauer, com sua fenomenologia do intelecto, enfatizou em diversas passagens de seus escritos o caráter instrumental desta noção, ou seja, que o intelecto fora criado apenas para perseguir os interesses da vontade, que consistem na busca pelo prazer, na fuga da dor e na reprodução, já que a Vontade em si nada tem de finalidades, por se tratar de um impulso metafísico não consciente. A vontade "põe a intelectualidade (entendimento + razão) ao seu serviço"13. E somente pela faculdade de conhecimento, que possibilita o mundo como representação, meio de ajuda indispensável, a ideia de homem pôde alcançar o máximo grau de elevação nas escalas

\footnotetext{
${ }^{10}$ CACCIOLA, M. L. M. O. Schopenhauer e o Inconsciente, p. 25.

${ }^{11}$ As Ideias em Schopenhauer são as "espécies determinadas ou as formas e propriedades originárias". Cf. SCHOPENHAUER, A. O mundo como vontade e representação. (Col. Os pensadores) p. 199. As ideias são, portanto, os graus intermediários de objetivação da Vontade, situados entre a coisa-em-si e o fenômeno.

${ }^{12}$ PERNIN, M. J. Schopenhauer: decifrando o enigma do mundo. p. 95.

${ }^{13}$ Idem. p. 87. 
das objetidades, o que permite a realização dos dois impulsos da vontade: "a nutrição e a propagação" ${ }^{\prime 14}$. Pelo conhecimento, o homem é capaz de executar as determinações que lhe são provocadas pelos motivos, que por estratégias chegam a romper os limites que poderiam dificultar a sua sobrevivência/conservação.

O conhecimento em geral, quer simplesmente intuitivo ou racional, provém, portanto, originariamente da Vontade e pertence à essência dos graus mais elevados de sua objetivação, como mera $\mu \eta \chi \alpha v \eta^{15}$, um meio para conservação do indivíduo e da espécie como qualquer órgão do corpo. Por conseguinte, originariamente a serviço da Vontade para realização dos seus fins, o conhecimento permanece-lhe quase sempre servil, em todos os animais e em quase todos os homens ${ }^{16}$.

Diferente das outras objetidades, a saber, animais não racionais e vegetais, onde a causalidade se dá, no primeiro, por motivos unicamente intuitivos e, no segundo, por excitações, no homem, enquanto agente, a mesma se dá mediante motivos acompanhados não somente de conhecimento intuitivo, mas também de conhecimento abstrato. A cada motivo, por sua vez, segue-se um movimento do corpo ou da vontade, já que Schopenhauer estabelece o corpo e a vontade como unos, dado o fato de a Vontade ter se objetivado. No entanto, não há identidade entre vontade e corpo quando se volta para a Vontade metafísica anterior ao processo de objetivação.

Ademais, a identidade do corpo com a vontade também se mostra, entre outras coisas, no fato de que todo movimento excessivo e veemente da vontade, isto é, cada afeto, abala imediatamente o corpo e sua engrenagem interior ${ }^{17}$.

Pela lei da motivação, o homem em seu agir dispõe do conhecimento abstrato, que lhe auxilia na consecução das determinações da vontade. As excitações só prevalecem no homem em sua dimensão vegetativa, e não em seus atos de vontade, que se dão mediante motivos. O homem, enquanto ideia/objetidade mais elevada da Vontade, tem em si, por meio da assimilação por dominação, todas as ideias/objetidades

\footnotetext{
${ }^{14}$ SCHOPENHAUER, A. O mundo como vontade e representação. Vol. II. p. 321.

${ }^{15}$ Astúcia e artimanha.

${ }^{16}$ SCHOPENHAUER, A. O mundo como vontade e representação, p. 127.

${ }^{17}$ Idem, p. 159. 
inferiores, que mesmo estando submetidas, continuam com seus esforços para exprimir a sua essência, ainda que na objetidade humana a mesma essência encontre a sua expressão. Porém, o fato de a ideia de homem ser a mais elevada, não significa afirmar que se trata de uma evolução dada partir das ideias/objetidades inferiores, dado o conceito de assimilação por dominação, pois Schopenhauer não fez nenhuma menção a uma espécie de evolucionismo, já que foi anterior a Darwin. Não foi objeto de suas preocupações filosóficas discorrer sobre como as diferentes formas de objetidades surgem na evolução histórica.

Embora no homem, como Ideia (platônica), a Vontade tenha encontrado sua objetivação mais distinta e perfeita, esta sozinha não poderia expressar sua essência. A Ideia de homem, para aparecer na sua atual significação, não podia se expor isolada e separadamente, mas tinha que ser acompanhada por uma sequência decrescente de graus em meio a todas as figuras animais, passando pelo reino vegetal e indo até o inorgânico. Todos esses reinos se complementam para a objetivação plena da Vontade ${ }^{18}$.

Há, pois, uma hierarquia dos diferentes graus de objetidade da Vontade e não uma evolução, pois a Vontade se objetiva de uma única vez na Ideia, ainda que isso não encerre o surgimento contínuo da matéria. Tal hierarquia das objetidades é semelhante àquela encontrada nas artes e nas virtudes morais.

\section{II - A concepção objetiva do intelecto}

Nos Complementos aos livros primeiro e segundo de $O$ mundo como vontade e representação, Schopenhauer apresentou diversos argumentos que apoiam sua visão objetiva do intelecto, isto é, mostrou sua concepção material não substancializada, definindo a noção como “[...] a função fisiológica de um órgão, o cérebro [...]”19. A partir dessa definição, torna-se possível verificar não somente os diversos aspectos que acentuam o caráter imperfeito do intelecto, dada a sua natureza física, isto é, fenomenal, mas também o cerne que ocasionou a ruptura realizada por Schopenhauer com a

\footnotetext{
${ }^{18}$ SCHOPENHAUER, A. O mundo como vontade e representação, p. 218-19.

${ }^{19}$ SCHOPENHAUER, A. O mundo como vontade e representação, Vol. II, p. 314. 
tradição filosófica ao mostrar o caráter temporal e ilimitado do intelecto, não mais entendido como eminentemente transcendental. Trata-se, por conseguinte, de um duplo ponto de vista acerca do intelecto, não contraditório, mas complementar, que assinala a diferença entre a visão de $O$ mundo como vontade e representação e a dos seus Complementos.

A todas essas imperfeições do intelecto se acrescenta ainda que envelhece juntamente com o cérebro, ou seja, igualmente a todas as funções fisiológicas, perde sua energia na idade avançada, com o que então acumula todas as suas imperfeições ${ }^{20}$.

Consoante às premissas da conclusão schopenhaueriana acerca do intelecto, este só pode conhecer em sucessão, ou seja, tornar-se consciente de uma coisa por vez devido a suas limitações. “A essa imperfeição do intelecto se deve o caráter rapsódico e com frequência fragmentário do curso de nosso pensamento [...]"21, que ao se debruçar sobre uma coisa ou objeto, todas as demais coisas e objetos deixam de existir. Isso aponta para o fato de que os pensamentos esquecidos podem não mais voltar à consciência, exceto quando estes estejam ligados aos interesses pessoais de um indivíduo, isto é, à sua vontade.

[...] Também a memória aumenta o nível de excitação da vontade. Mesmo sendo fraca em outros casos, conserva com perfeição o que tem valor para a paixão dominante. O namorado não esquece nenhuma ocasião propícia; o ambicioso, nenhuma circunstância que se adeque aos seus planos; o avarento não esquece nunca a ofensa que sofreu; nem o orgulhoso a ofensa feita; o vaidoso guarda cada palavra de elogio e até a mais mínima distinção que lhe foi feita ${ }^{22}$.

Segundo a concepção objetiva do intelecto em Schopenhauer, este nada mais é que uma produção físico-química cerebral e, por sua vez, está limitado pelas condições dessa fisiologia, não sendo o fundamento metafísico da realidade, "dirigido unicamente à conservação do indivíduo e para lhe auxiliar somente para isso"23. Estaria, ainda, num segundo momento, dependente não somente dessa fisiologia, mas também, enquanto

\footnotetext{
${ }^{20}$ SCHOPENHAUER, A. O mundo como vontade e representação, Vol. II, p. 261.

${ }^{21}$ Idem, p. 173.

${ }^{22}$ Idem, p. 261.

${ }^{23}$ Idem, p. 182. 
faculdade de conhecer, depende do mundo externo/objeto, pois sem este, as formas do princípio de razão tornar-se-iam vazias pela ausência de conteúdo sensível. Assim, o conhecimento de fenômeno obtido mediante a ligação das formas do princípio de razão com a experiência não equivale ao conhecimento da essência das coisas que, portanto, dá-se não mediante o princípio de razão, mas através da experiência interna.

[...] Estamos justificados a afirmar que todo o mundo objetivo, tão limitado no espaço, infinito no tempo e insondável em sua perfeição, na realidade é somente um certo movimento ou afetação da massa cerebral no crânio ${ }^{24}$.

O intelecto, portanto, "é a faculdade de representação estruturada pelo princípio de razão suficiente que desempenha um papel exclusivamente perceptivo e pragmático

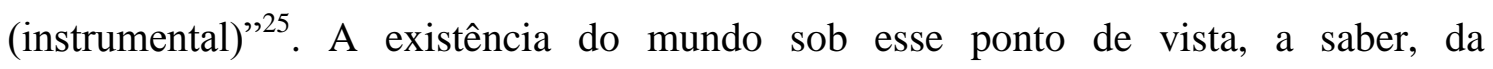
representação, depende unicamente de uma consciência que o conceba, como também a existência do mundo está vinculada à existência desse indivíduo. Cessando o indivíduo, desaparece o mundo da representação. Por ser restrito apenas ao conhecimento do fenômeno, o intelecto chega ao limite da sua possibilidade de conhecer quando começa a Vontade como coisa-em-si.

O filósofo de Danzig também sinaliza para a diversidade de graus de intelecto que variam de acordo com as objetidades da Vontade, cuja "diferenciação obedece não à vontade, mas à maior ou menor extensão da esfera de conhecimento" ${ }^{26}$, pois que não há diferença em termos de essência. Nos animais, não há separação entre querer e conhecer, pois eles seguem as orientações inconscientes da Vontade que neles se objetiva. Nestes, há apenas conhecimento intuitivo, que lhes permite “[...] uma vaga percepção do seu entorno imediato, de que resultam os motivos para suas ações dirigidas apenas à sua conservação" ${ }^{, 27}$. Um conhecimento que lhes faz pressentir o perigo, mas completamente desprovido de consciência, isto é, não há aí um saber acerca da finalidade do seu agir/movimento. Os animais estão, pois, imersos no presente e na inconsciência de sua tarefa, pois, pela ausência do conhecimento abstrato, não podem

\footnotetext{
${ }^{24}$ SCHOPENHAUER, A. O mundo como vontade e representação, Vol. II, p. 314.

${ }^{25}$ CACCIOLA, M. L. M. O. Schopenhauer e o Inconsciente, p. 20.

${ }^{26}$ Idem, ibidem.

${ }^{27}$ SCHOPENHAUER, A. O mundo como vontade e representação, Vol. II, p. 320. 
prever o futuro e nem retornar ao passado, no sentido de recordá-lo ou de tê-lo como motivo de sua ação.

Assim, o pássaro constrói o ninho para suas crias que ele ainda não conhece; o castor ergue uma casa cujo fim lhe é desconhecido; a formiga, o hamster e a abelha reúnem provisão para o inverno desconhecido; a aranha e a formiga-leão preparam, como que por ponderada astúcia, armadilhas para a futura presa incógnita; os insetos põem seus ovos lá onde a futura larva encontrará futuro alimento ${ }^{28}$.

O cérebro humano é considerado o mais perfeito, por isso a faculdade intelectual tornou-se mais complexa, isto é, alcançou uma enorme diferença, em termos de graus e forças de conhecimento, que possibilitou a diversidade dos motivos que, por sua vez, faz com que a vontade se torne consciente de si mesma a partir de diferentes modos. Por conta dessa ascensão cerebral, as necessidades se tornaram cada vez maiores e mais complicadas, distanciando-se dos motivos reais, uma vez que com a faculdade de razão fez-se perder "[...] aquela segurança e infalibilidade das exteriorizações da Vontade [...] $]^{, 29}$, que permitiram ao homem a arte da dissimulação e do fingimento, já que entre ele e a vontade passam a se interpor motivos imaginários, que se distanciam dos motivos originários. Se as premissas de Schopenhauer acerca da concepção de caráter não o tomassem como originário, imutável e inexplicável, a arte de fingir e de dissimular, decorrente da faculdade de razão, ainda se constituiria em grave entrave para a educação, que não poderia ter a certeza quanto à eficácia dos seus métodos pedagógicos, no que se refere à possibilidade de modificação do caráter dos indivíduos.

Schopenhauer considera o advento da razão como indissociável do advento da dissimulação e da ilusão. Pode-se dizer que, nesse momento, se percebe traços de "perversidade" na razão - segundo a visão de Schopenhauer. [...] ao mesmo tempo em que observa que, no cume da pirâmide da vontade, o homem alia a complexidade intelectual à capacidade de dissimulação $0^{30}$.

Assim sendo, um intelecto poderoso, como aquele encontrado nos tipos superiores de homem definidos por Schopenhauer, a saber, o gênio, o compassivo e o

\footnotetext{
${ }^{28}$ SCHOPENHAUER, A. O mundo como vontade e representação, p. 227.

${ }^{29}$ SCHOPENHAUER, A. O mundo como vontade e representação, p. 217.

${ }^{30}$ BRUM, J. T. O pessimismo e suas vontades: Schopenhauer e Nietzsche, p. 29. 
santo, torna-se um obstáculo para a Vontade enquanto manifestação. Esse obstáculo diz respeito ao fato de o intelecto condicionar a forma pela qual a Vontade se manifesta, mas não alterar o seu conteúdo originário, "pois o excessivo desenvolvimento da inteligência torna-se diretamente um obstáculo para a firmeza do caráter e a resolução da vontade" 31 . Porém, como a natureza é aristocrática e econômica naqueles indivíduos que vêm a dotar com um poderoso intelecto, capaz de feitos admiráveis, não haveria, segundo Schopenhauer, a necessidade de dotar com tal intelecto os homens que "passam suas vidas dedicados a trabalhos corporais e puramente mecânicos" "32, já que a estes seriam suficientes um intelecto que assegurasse apenas a conservação do corpo e a propagação da espécie.

Convêm ressaltarmos que Schopenhauer concebe materialmente o cérebro como um órgão central do sistema nervoso, que possui uma função fisiológica denominada intelecto, que permite unicamente a intuição do mundo externo nas formas do princípio de razão, ou seja, do mundo como representação/fenômeno, e que por este motivo não possibilita ao intelecto, salvo as exceções já apontadas, conhecer a coisa-em-si. Assim sendo, o mundo como representação, primeiro ponto de vista sobre o mundo, nada mais é do que resultado dessa fisiologia, estando no próprio corpo, enquanto phýsis, as condições de sua possibilidade. O intelecto enquanto faculdade de conhecimento assume uma função prática, destinado a perseguir os fins da vontade individual mediante a apresentação de motivos. Por tal afirmação, o intelecto passa a ter uma função meramente servil.

Desta consideração objetiva do intelecto e sua origem se deduz que está destinado a perseguir os fins em cuja consecução se baseiam a vida individual e sua propagação, e de modo algum a reproduzir o ser em si das coisas e do mundo, que existe a margem do conhecimento. [...] Antes bem, o intelecto, ao proceder da vontade, está destinado somente a servi-la, a captar os motivos: para isso tendo sido criado, e disto tenha uma tendência prática ${ }^{33}$.

Então, segundo o ponto de vista objetivo, o intelecto é cérebro, objetidade da vontade na totalidade do corpo. Por tal eminência do intelecto humano, diz

\footnotetext{
${ }^{31}$ SCHOPENHAUER, A. O mundo como vontade e representação. Vol. II, p. 324.

${ }^{32}$ SCHOPENHAUER, A. O mundo como vontade e representação. Vol. II, p. 325.

${ }^{33}$ Idem, p. 326. 
Schopenhauer:

[...] o cérebro ascende até o intelecto, ultrapassa seus limites por meio da forma cognitiva da causalidade e assim nasce nele a intuição como consciência de outras coisas, como uma imagem dos seres no espaço e no tempo, que muda conforme a causalidade ${ }^{34}$.

Além do ponto de vista objetivo do intelecto, onde este é concebido como função cerebral, é importante ressaltar que o cérebro também pode ser tomado como objeto de estudo científico-experimental, como fizeram Cabanis, Bichat, Gall, Flourens, Magendie, Charles Bel. Há, por conseguinte, segundo Pernin ${ }^{35}$, o ponto de vista subjetivo, em que o intelecto nos é dado na consciência, ou seja, o sujeito do conhecimento dá-se conta de que representa, tornando-se único sustentáculo do mundo como representação e, ao mesmo tempo, descobre-se como sujeito volitivo, embora em ambas as perspectivas acerca do intelecto, seja objetiva ou subjetiva, a verdade é que o eu consciente é a mesma coisa que o cérebro, de um outro ponto de vista. Independente do ponto de vista que seja pensado, o intelecto não transpõe sua natureza fenomenal e fisiológica, já que não é o em-si, sendo apenas função e resultado de um movimento cerebral.

[...] Pois é uma função do cérebro que, junto com os nervos e a medula espinhal conectados a ele, constituem um simples fruto, um produto e até um parasita do resto do organismo, na medida em que não intervém em sua engrenagem interna senão que somente para servir a finalidade da autoconservação, regulando suas relações com o mundo exterior ${ }^{36}$.

Schopenhauer, ao ter discorrido sobre o conceito de intelecto, enfatizando seu caráter de subordinação à Vontade irracional, não deve ser entendido, conforme erroneamente se concluiu, como o filósofo que se opõe radicalmente aos ditames do intelecto.

Ao postular como essencial o querer viver, a racionalidade perde seu poder absoluto sobre si mesma e sobre o mundo, deixando entrever

\footnotetext{
${ }^{34}$ Idem, p. 315.

${ }^{35}$ PERNIN, M. J. Schopenhauer: decifrando o enigma do mundo. p. 93.

${ }^{36}$ SCHOPENHAUER, A. O mundo como vontade e representação. Vol. II. p. 239. 
algo outro que se lhe contrapõe. O "eu quero" toma o lugar do "eu penso" cartesiano, abrindo espaço para a admissão de um impensado $[\ldots]^{\prime 37}$.

A oposição empreendida por Schopenhauer não o impediu de reconhecer as potencialidades do intelecto, já que o filósofo apenas reconheceu um lugar secundário do mesmo diante da Vontade, cega e incausada, que não se submete em essência, mas apenas na forma de sua manifestação, às determinações da inteligência em certos indivíduos .

A filosofia de Schopenhauer subverte a ordem esperada do racionalismo. Nessa medida, pode-se dizer que ela comporta o absurdo: as marionetes do teatro acreditam ser atraídas para a frente, em direção aos fins, mas atrás delas, ou antes, escondida nelas, a vontade ávida as empurra. [...] O homem não tem uma conduta moral regulada pela razão, como se podia esperar ${ }^{38}$.

Tal constatação sinaliza que Schopenhauer é apenas irracionalista no plano metafísico, porém racionalista no plano fenomênico, pois ele apresentou três aspectos da razão ${ }^{39}$, bem descritos por Jair Barboza. No primeiro aspecto, temos a razão epistemológica, encontrada no Livro I do Mundo, entendida como faculdade de abstração, que forma representações de representações, isto é, os conceitos, que têm origem nas intuições. Conceitos que se tornam, pois, a matéria do conhecimento científico. Em segundo, o aspecto prático da razão, remetendo-nos aos epicuristas e estóicos. Esta razão poderia ser denominada de Sabedoria de vida, que faz com que os indivíduos guardem conhecimentos para a prática de vida, onde se evitam excitações desnecessárias que possam terminar por acentuar seus sofrimentos; sabedoria esta empregada em busca do bem-estar pessoal mediante uma vida regrada, âmbito em que a prudência na convivência com o outro almeja uma boa qualidade de vida, ainda que não haja uma supressão definitiva dos sofrimentos advindos do fato de todos os homens serem uma objetidade da Vontade Metafísica. E, em terceiro lugar, a razão mística, que

\footnotetext{
${ }^{37}$ CACCIOLA, M. L. M. O. Atualidade de Schopenhauer: o eu quero abre caminho ao inconsciente, p. 34.

${ }^{38}$ PERNIN, M. J. Schopenhauer: decifrando o enigma do mundo, p. 87.

${ }^{39}$ Cf. SCHOPENHAUER, A. O mundo como vontade e representação. Tradução: Jair Barboza. São Paulo: UNESP, 2005.
} 
permite a visão do todo da vida, conduzindo ao processo de negação da vontade. Porém, esse conhecimento do todo não se dá mediante o princípio de razão, que está vinculado ao conhecimento ligado à afirmação da vontade. Este conhecimento é peculiar ao santo e ao compassivo, que ao alcançarem a visão do todo da vida, conseguem se separar da vontade em suas manifestações. Com essas assertivas filosóficas, que são demonstradas a partir de experimentos, mas de amplos estudos e observação atenta do mundo, Schopenhauer golpeou a metafísica tradicional, que atribuía poderes ilimitados ao intelecto em termos de conhecimento e moral. Por ser físico, "aqui entendido como fenomenal e não como forte" 40 , o intelecto, com os tempos idos de um indivíduo, chega ao esgotamento de suas forças em função de sua natureza biológica, ao contrário da Vontade, que é imutável e intemporal.

\section{Referências}

BRUM, José Thomaz. O pessimismo e suas vontades: Schopenhauer e Nietzsche. Rio de Janeiro: Rocco, 1998.

CACCIOLA, Maria Lúcia Melo e Oliveira. Schopenhauer e a questão do dogmatismo. São Paulo: UNESP, 1994.

. Schopenhauer e o inconsciente. In: (Org.) KNOBLOCH, Felícia. O inconsciente: várias leituras. São Paulo: Escuta, 1991.

Atualidade de Schopenhauer: o eu quero abre caminho ao inconsciente.

In: Nietzsche/Schopenhauer - o outro lado da racionalidade. Revista Mente \& Cérebro. São Paulo: Duetto Editorial, edição no 03. ISBN 978-85-99535-26-4.

PERNIN, Marie José. Schopenhauer: decifrando o enigma do mundo. Tradução de Lucy Magalhães. Rio de Janeiro: Jorge Zahar, 1995.

SANTANA, Kleverton Bacelar. Sobre a IV motivação na psicologia de Schopenhauer. In: REDYSON, Deyve. Arthur Schopenhauer no Brasil: em memória dos 150 anos da morte de Schopenhauer. João Pessoa: Ideia, 2010.

SCHOPENHAUER, Arthur. O mundo como vontade e representação. Tradução: Jair Barboza. São Paulo: UNESP, 2005.

\footnotetext{
${ }^{40}$ PERNIN, M. J. Schopenhauer: decifrando o enigma do mundo, p. 96. 
ANDRÉ LUIZ SIMÕES PEDREIRA

O mundo como vontade e representação. Livro III. Trad: Wolfgang Leo

Maar. São Paulo: Abril Cultural, 1980. (Os pensadores)

El mundo como voluntad y representación II (Complementos).

Tradução: Pilar López de Santa Maria. Madrid: Editorial Trotta, 2005.

WEISSMANN, Karl. Vida de Schopenhauer. Belo Horizonte: Editora Itatiaia, 1980.

Recebido: $26 / 02 / 14$

Received: 02/26/14

Aprovado: $10 / 03 / 14$

Approved: 03/10/14 